\title{
Association of Impaired Functional Status at Hospital Discharge and Subsequent Rehospitalization
}

\author{
Erik H. Hoyer, MD ${ }^{1 *}$, Dale M. Needham, MD, PhD¹, Levan Atanelov, MD¹, Brenda Knox, MS, SLP², \\ Michael Friedman, PT, $\mathrm{MBA}^{3}$, Daniel J. Brotman, MD ${ }^{4}$
}

\begin{abstract}
${ }^{1}$ Department of Physical Medicine and Rehabilitation, Johns Hopkins University, Baltimore, Maryland; '2Department of Physical Medicine and Rehabilitation, MedStar Health System, Baltimore, Maryland; 'Department of Physical Medicine and Rehabilitation, Johns Hopkins Hospital, Baltimore, Maryland; ${ }^{4}$ Division of General Internal Medicine, Johns Hopkins University, Baltimore, Maryland.
\end{abstract}

OBJECTIVE: To determine whether functional status near the time of discharge from acute care hospitalization is associated with acute care readmission.

PATIENTS AND METHODS: Retrospective cohort study of 9405 consecutive patients admitted from an acute care hospital to an inpatient rehabilitation facility between July 1 , 2006 and December 31, 2012. Patients' functional status at admission to the rehabilitation facility was assessed by the Functional Independence Measure (FIM) score, and divided into low, middle, or high functional status. The main outcome was readmission to an acute care hospital within 30 days of acute care discharge (for all patients and by subgroup according to diagnostic group: medical, orthopedic, or neurologic).

RESULTS: There were 1182 (13\%) readmissions. FIM score was significantly associated with readmission, with adjusted odds ratios (ORs) and 95\% confidence intervals
(Cls) for low and middle versus high FIM score category of 3.0 (2.5-3.6; $P<0.001)$ and 1.5 (95\% Cl: 1.3-1.8; $P<0.001)$, respectively. This relationship between FIM score and readmission held across diagnostic category. Medical patients with low functional status had the highest readmission rate (OR: 29\%; 95\% Cl: 25\%-32\%) and an adjusted OR for readmission of 3.2 (95\% Cl: $2.4-4.3, P<0.001)$ compared to medical patients with high FIM scores.

CONCLUSIONS AND RELEVANCE: For patients admitted to an acute inpatient rehabilitation facility, functional status near the time of discharge from an acute care hospital is strongly associated with acute care readmission, particularly for medical patients with greater functional impairments. Reducing functional status decline during acute care hospitalization may be an important strategy to lower readmissions. Journal of Hospital Medicine 2014;9:277282. (C) 2014 Society of Hospital Medicine
Federally mandated pay-for-performance initiatives promote minimizing 30-day hospital readmissions to improve healthcare quality and reduce costs. Although the reasons for readmissions are multifactorial, many patients are readmitted for a condition other than their initial hospital admitting diagnosis. ${ }^{1}$ Impairments in functional status experienced during acute care hospitalization contribute to patients being discharged in a debilitated state and being vulnerable to postdischarge complications and potentially hospital readmission. ${ }^{2}$ As such, decreased functional status may be an important and potentially modifiable risk factor for acute care hospital readmission. ${ }^{3}$

Previous studies have suggested that impaired functional status may be an important predictor of rehospitalization. ${ }^{4-7}$ However, inferences from existing studies are limited because they did not consider functional status as their primary focus, they only consid-

*Address for correspondence and reprint requests: Erik H. Hoyer, MD, 600 N Wolfe Street, Phipps 174, Baltimore, MD 21287; Telephone: 410502-2438; Fax: 410-502-2419; E-mail: ehoyer1@jhmi.edu

Additional Supporting Information may be found in the online version of this article.

Received: November 8, 2013; Revised: December 18, 2013; Accepted: December 23, 2013

2014 Society of Hospital Medicine DOI 10.1002/jhm.2152

Published online in Wiley Online Library (Wileyonlinelibrary.com). ered specific patient populations (eg, stroke) or readmissions occurring well beyond the 30-day period defined by federal pay-for-performance standards. ${ }^{4-}$ 6,8-10 Our objective was to evaluate the association between functional status near the time of discharge from acute care hospital and 30-day readmission for patients admitted to an acute inpatient rehabilitation facility. As a secondary objective, we sought to investigate the relationship between functional status and readmission by diagnostic category (medical, neurologic, or orthopedic).

\section{METHODS}

\section{Study Population and Setting}

We conducted a single-center, retrospective study of patients admitted to an inpatient rehabilitation facility at a community hospital between July 1, 2006 and December 31, 2012. This facility provides intensive rehabilitation consisting of 3 hours of therapy per day, skilled nursing care on a 24-hour basis, and medical care by a physiatrist. We excluded patients who died during inpatient rehabilitation $(n=15,0.2 \%)$ and patients not admitted directly from an acute care setting $(\mathrm{n}=178,2.0 \%)$.

\section{Data Source and Covariates}

Data were derived from the Uniform Data System for Medical Rehabilitation (UDSMR), which is an 
administrative database providing the following data upon admission to an inpatient rehabilitation facility $^{11-13}$ : age, gender, race/ethnicity, marital status, the discharge setting, the admission Functional Independence Measure (FIM) score (details further below), and admission diagnostic category as defined by the primary discharge diagnosis from the acute care hospital and grouped by functional related groups (a case-mix system for medical rehabilitation). ${ }^{2,14}$ The $3 \mathrm{M}$ ClinTrac management software (3M, St. Paul, MN), used for mandatory reporting to the State of Maryland, provided all-payer-refined diagnosis related group (APRDRG) and severity of illness (SOI) combinations (a tool to group patients into clinically comparable disease and severity-of-illness categories expected to use similar resources and experience similar outcomes). The University HealthSystem Consortium (UHC) database provided national readmission rates for all APRDRG-SOI combinations using a methodology that has been previously described. ${ }^{15,16}$ Expected readmission rates for APRDRG-SOI combinations served as a patient risk stratification tool based on clinical logic that evaluates age, comorbidities, principal diagnosis during hospitalization, and procedures conducted during hospitalization. ${ }^{17}$

\section{Primary Outcome: Acute Care Readmission}

The primary outcome was all-cause acute care readmission, defined as patient transfer to an acute care hospital during inpatient rehabilitation within 30 days from admission to inpatient rehabilitation. The care model for our inpatient rehabilitation unit is such that when patients become sick or develop a complication, they are admitted directly to a clinical unit (eg, intensive care unit) at the community hospital through a rapid-response intervention, or the physiatrist arranges with an admitting inpatient attending to accept the patient directly to his or her service.

\section{Primary Exposure: Functional Independence Measure}

Functional status was measured using the FIM score. ${ }^{18}$ The FIM score is an 18 -item measure of functional status, with each item scored on a scale from 1 to 7 (dependent to independent). Various aspects of motor function and cognitive function are assessed. The FIM has been validated and shown to be reliable and reproducible. ${ }^{13,19,20}$ By definition for the FIM instrument, admission FIM scores are assessed by trained multidisciplinary personnel first over the 72 hours of the rehabilitation stay, and for this study served as a proxy for patient functional status upon discharge from the acute care setting in our analysis. This 72-hour time window allows for full assessment by therapists and nurses; however, in clinical practice at the inpatient rehabilitation unit involved in this study, much of the FIM assessment occurs within the first 24 hours of the rehabilitation stay. For our analysis, we divided FIM scores into low, medium, and high functional groups. The thresholds for these groups were based on total FIM score tertiles from a prior study $-<60,60$ to 76 , and $>76 .{ }^{16}$ As a secondary analysis we created 6 subscales of the overall FIM score based on previous research. These subscales included: transfers (transfer to chair/wheelchair, toilet, and tub/shower), locomotion (walking and stairs), self-care (eating, grooming, bathing, dressing, and toileting), sphincter control (bladder and bowel management), communication (comprehension and expression), and social cognition (social interaction, problem solving, and memory). ${ }^{21}$

\section{Statistical Analysis}

To evaluate differences in patient characteristics by diagnostic category, analysis of variance and $\chi^{2}$ tests were used for continuous and dichotomous variables, respectively. Logistic regression was used to evaluate the association between FIM score category and readmission status, adjusting for potentially confounding variables available from the UDSMR and UHC databases. We used interaction terms to test whether the association between the FIM score and readmissions varied significantly across diagnostic categories and by age. As a secondary analysis, we modeled FIM score as a continuous variable. We expressed the odds ratio in this analysis per 10-point change in FIM, because this represents a clinically relevant change in function. ${ }^{22}$ Logistic regression was also used to evaluate the association between FIM subscale scores (transfers, locomotion, self-care, sphincter control, communication, and social cognition) and readmission status. Statistical significance was defined as a 2-sided $P<0.05$. Data were analyzed with $\mathrm{R}$ (version 2.15.0; http://www.r-project.org). This study was approved by the Johns Hopkins and MedStar Health System institutional review boards.

\section{RESULTS}

\section{Readmitted Patients and Diagnostic Categories}

A total of 9405 consecutive eligible patients were admitted to the acute inpatient rehabilitation facility between July 1, 2006 and December 31, 2012. A total of $1182(13 \%)$ patients were readmitted back to an acute care hospital from inpatient rehabilitation. Median (interquartile range) time to readmission from acute care hospital discharge was 6 days (3-10 days), and median length of stay for patients who were discharged to the community from inpatient rehabilitation was 8 days (6-12 days).

Table 1 shows characteristics of all inpatient rehabilitation patients by diagnostic category. For the neurologic category, the most common primary diagnoses were stroke and spinal cord injury; for the medical category, infection, renal failure, congestive heart failure, and chronic obstructive pulmonary disease; and for the orthopedic category, spinal arthrodesis, knee 
TABLE 1. Characteristics of All Patients by Diagnostic Category*

\begin{tabular}{|c|c|c|c|c|c|}
\hline \multirow[b]{2}{*}{ Characteristic } & \multirow[b]{2}{*}{ All Patients, N = 9405} & \multicolumn{3}{|c|}{ Diagnostic Category } & \multirow[b]{2}{*}{$P$ Value $^{\dagger}$} \\
\hline & & Neurologic, $n=3706$ & Medical, $n=2135$ & Orthopedic, $n=3564$ & \\
\hline Age, y & $67.8(14.2)$ & $66.7(15.3)$ & $67.0(14.9)$ & $69.3(12.4)$ & $<0.001$ \\
\hline Race & & & & & $<0.001$ \\
\hline Caucasian & $6,106(65 \%)$ & $2344(63 \%)$ & $1,320(62 \%)$ & $2,442(69 \%)$ & \\
\hline African American & $2,501(27 \%)$ & $984(27 \%)$ & $658(31 \%)$ & $859(24 \%)$ & \\
\hline APRDRG-SOl expected readmission rate & $18.0(7.4)$ & $20.5(6.8)$ & $21.3(7.5)$ & $13.5(5.6)$ & $<0.001$ \\
\hline Total admission FIM score & $68.7(17.2)$ & $60.4(18.6)$ & $69.1(15.5)$ & $77.2(11.7)$ & $<0.001$ \\
\hline
\end{tabular}

NOTE: Abbreviations: APRDRG, all-payer-refined diagnosis-related group; FIM, Functional Independence Measure; SOI, severity of illness.

${ }^{*}$ Continuous variables are presented as mean (standard deviation); dichotomous variables are presented as $n(\%)$.

${ }^{\dagger} P$ values calculated using analysis of variance and $\chi^{2}$ tests for continuous and dichotomous variables, respectively.

and hip replacements. Mean FIM scores were lowest and highest for patients admitted with a primarily neurologic and orthopedic diagnosis, respectively.

\section{FIM Score Category and Risk of Readmission}

Figure 1 shows that patients in the low admission FIM score category had the highest unadjusted rate of readmission for each diagnostic category. In unadjusted analysis, Table 2 shows that younger age, male sex, APDRG-SOI expected readmission rate, and orthopedic and medical diagnostic categories were associated with readmission. As a continuous variable, FIM scores were linearly associated with readmission (Figure 2), with an unadjusted odds ratio (OR) and $95 \%$ confidence interval (CI) of 1.4 (1.4-1.4, $P<0.001)$ for a 10 -point decrease in FIM. Compared to patients with high admission FIM scores, patients with low and middle FIM scores had higher unadjusted odds of readmission (OR: 4.0; 95\% CI: 3.44.7; $P<0.001$ and OR: $1.8 ; 95 \%$ CI: 1.5-2.1; $P<0.001$, respectively). Mean FIM subscale scores for patients readmitted versus not readmitted were transfers (5.3 vs 7.0, $P<0.001)$, locomotion (1.6 vs $2.3, P<0.001)$, self-care $(17.0$ vs $20.8, P<0.001)$,

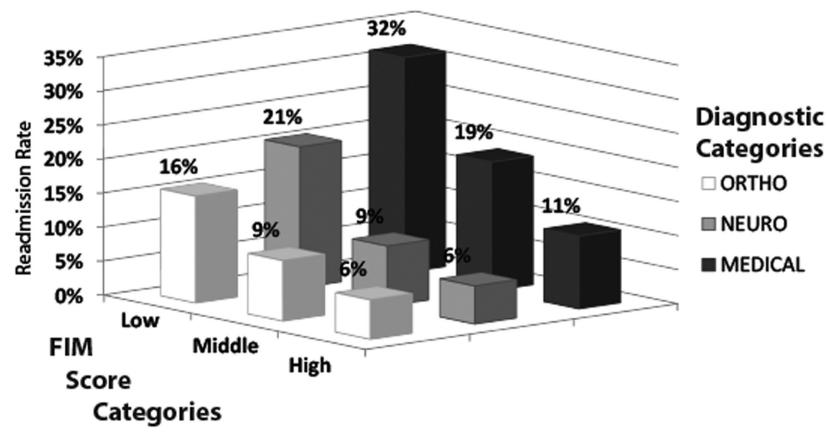

FIG. 1. Proportion of patients readmitted by FIM score and diagnostic category. Unadjusted proportion of inpatient rehabilitation patients readmitted to acute care hospital by diagnostic category and FIM score category (high: $>76$ points, middle: $60-76$ points, and low: $<60$ points). Abbreviations: FIM, Functional Independence Measure. communication (10.6 vs $11.5, P<0.001$ ), and social cognition (15.1 vs $16.6, P<0.001)$.

\section{Multivariable and Subset Analyses}

Patients with a primary medical diagnosis had higher odds of readmission to the hospital, (OR: 1.8; 95\% CI: 1.6-2.1, $P<0.001)$, relative to patients with a neurologic or orthopedic diagnosis (Table 2). Across all diagnoses, the adjusted odds ratios (95\% CIs) for the low and middle versus high FIM score category were $3.0(2.5-3.6 ; \quad P<0.001)$ and $1.5 \quad(1.3-1.8$; $P<0.001$ ) respectively (Table 2 ). When modeled as a continuous variable, a 10-point decrease in FIM score was associated with a significantly increased adjusted readmission rate (OR: 1.4; 95\% CI: 1.3-1.4; $P<0.001)$. In adjusted analysis including all subscales of the FIM, only the physical subscales, transfers $(P<0.001)$, locomotion $(P=0.002)$, and self-care $(P<0.001)$, were significantly associated with readmission. For each diagnostic category, there were similar significant associations between admission FIM score group and readmission status (Table 3). The odds of readmission by FIM score did not differ significantly across the 3 major diagnostic categories $(P=0.20$ for interaction term), suggesting that the effect of functional status was similar across various types of patients. We also did not observe a statistical interaction between age and FIM score group in predicting readmission $(P=0.58)$. Patients in the lowest FIM group with a medical diagnosis had the highest adjusted readmission rate of $28.7 \%$ (Table 3 ).

\section{DISCUSSION}

In this study of 9405 consecutive patients admitted from acute care hospitals to a single inpatient rehabilitation facility, we investigated the association between functional status and readmission to an acute care hospital. We found that low functional status near the time of acute care hospital discharge was strongly associated with higher readmission rates. This 
TABLE 2. Association Between Patient Characteristics, FIM Scores, and 30-Day Readmission Status*

\begin{tabular}{|c|c|c|c|c|c|c|}
\hline \multirow[b]{2}{*}{ Characteristic } & \multirow[b]{2}{*}{ All Patients, $N=9405$} & \multirow[b]{2}{*}{ Readmitted, $n=1,182$} & \multicolumn{2}{|c|}{ Bivariable Analysis $^{\dagger}$} & \multicolumn{2}{|c|}{ Multivariable Analysis $^{\dagger}$} \\
\hline & & & OR $(95 \% \mathrm{Cl})$ & $P$ Value & OR (95\% Cl) & $P$ Value \\
\hline Age, y & $68.0(14.2)$ & $66.4(14.5)$ & $0.9(0.9-1.0)$ & $<0.001$ & $0.9(0.9-1.0)$ & $<0.001$ \\
\hline Male & $3,431(42 \%)$ & $637(54 \%)$ & $1.6(1.4-1.8)$ & $<0.001$ & $1.3(1.1-1.5)$ & $<0.001$ \\
\hline \multicolumn{7}{|l|}{ Race } \\
\hline Caucasian & $5,340(65 \%)$ & $766(65 \%)$ & 1.0 & & 1.0 & \\
\hline African American & $2,177(26 \%)$ & $324(27 \%)$ & $1.0(0.9-1.2)$ & 0.60 & $1.0(0.8-1.1)$ & 0.75 \\
\hline Other & $706(9 \%)$ & $92(8 \%)$ & $0.9(0.7-1.1)$ & 0.41 & $0.8(0.6-1.0)$ & 0.12 \\
\hline Married & $3,775(46 \%)$ & $555(47 \%)$ & $1.0(0.9-1.2)$ & 0.50 & $1.0(0.9-1.2)$ & 0.67 \\
\hline \multicolumn{7}{|l|}{ Admission diagnosis category } \\
\hline Neurologic & $3,205(39 \%)$ & $501(42 \%)$ & 1.0 & & 1.0 & \\
\hline Medical & $1,726(21 \%)$ & $409(35 \%)$ & $1.5(1.3-1.7)$ & $<0.001$ & $1.8(1.6-2.1)$ & $<0.001$ \\
\hline Orthopedic & $3,292(40 \%)$ & $272(23 \%)$ & $0.5(0.5-0.6)$ & $<0.001$ & $1.3(1.1-1.6)$ & 0.005 \\
\hline APDRG-SOI expected readmission rate & $17.4(7.1 \%)$ & $22.2(8.0 \%)$ & $1.1(1.1-1.1)$ & $<0.001$ & $1.1(1.0-1.1)$ & $<0.001$ \\
\hline \multicolumn{7}{|l|}{ Total FIM score category } \\
\hline High FIM, > 76 points & $3,517(43 \%)$ & $257(22 \%)$ & 1.0 & & 1.0 & \\
\hline Middle FIM, 60-points & $2,742(33 \%)$ & $353(30 \%)$ & $1.8(1.5-2.1)$ & $<0.001$ & $1.5(1.3-1.8)$ & $<0.001$ \\
\hline Low FIM, <60 points & $1,964(24 \%)$ & $572(48 \%)$ & $4.0(3.4-4.7)$ & $<0.001$ & $3.0(2.5-3.6)$ & $<0.001$ \\
\hline
\end{tabular}

NOTE: Abbreviations: APRDRG, all-payer-refined diagnosis-related group; Cl, confidence interval; FIM, Functional Independence Measure; OR, odds ratio; SOI, severity of illness.

*Binary and categorical data are presented as n (\%), and continuous variables are represented as mean (standard deviation). Proportions may not add to $100 \%$ due to rounding.

${ }^{\dagger}$ Calculated using logistic regression analysis.

relationship was consistently observed across major patient diagnostic categories, with low functioning medical patients having the highest rate of readmission $(28.7 \%)$. Efforts to maintain or improve functional status during acute care hospitalization may be an important modifiable risk factor for acute care hospital readmission.

Previous studies have suggested that functional status may serve as an indicator of physiological reserve, and therefore vulnerability to medical complications and readmission. ${ }^{6,16,23-25}$ Physiologic reserve refers to a person's ability to endure acute illness and is influenced by a number of factors, such as the adequacy of oxygen delivery to tissues, cardiovascular health, immune state, and nutritional status. ${ }^{26}$ We found that motor subscales of the FIM score (transfers, locomotion, and self-care), but not the other subscales, were independently associated with readmissions, which may suggest that lower motor scores are a stronger marker of physiologic reserve. ${ }^{10,16,27}$ Although not our primary focus, we did note in our multivariable models that after adjusting for functional status, patients in a medical diagnostic category had higher readmission rates compared to patients with a primary neurologic or orthopedic diagnosis, but the impact of FIM score was consistent across all these diagnostic categories. We speculate that medical conditions that result in hospitalization, such as sepsis or acute kidney
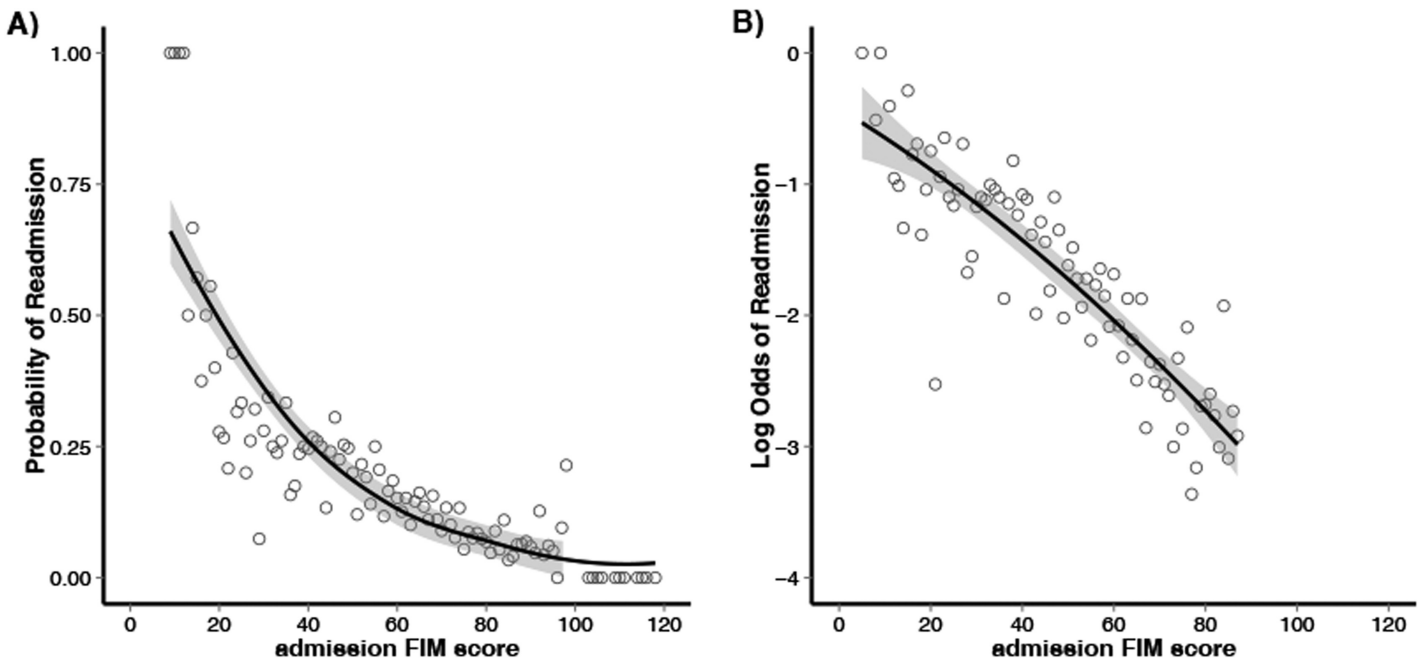

FIG. 2. Association between admission FIM scores and readmission. (A) A plot of admission FIM score and the observed probability of readmission (open circles), with a locally weighted scatterplot smoothing line and 95\% confidence bands (grey shading). (B) A linear relationship between FIM score and log odds of readmission to acute care hospital. Abbreviations: FIM, Functional Independence Measure. 
TABLE 3. Adjusted Association of FIM Score With 30-Day Readmissions by Diagnostic Category

\begin{tabular}{|c|c|c|c|c|}
\hline & \multirow[b]{2}{*}{ No. } & \multicolumn{2}{|c|}{ Multivariable Analysis* } & \multirow{2}{*}{$\begin{array}{c}\text { Adjusted } \\
\text { Readmission Rates }{ }^{\dagger} \\
\%(95 \% \mathrm{Cl})\end{array}$} \\
\hline & & OR $(95 \% \mathrm{Cl})$ & $P$ Value & \\
\hline \multicolumn{5}{|l|}{ Neurologic } \\
\hline High FIM (>76 points) & 755 & 1.0 & & $7.3(4.7-10.0)$ \\
\hline Middle FIM (60-76 points) & 1,283 & $1.4(1.0-2.1)$ & 0.06 & $9.1(7.0-11.1)$ \\
\hline Low FIM (<60 points) & 1,668 & $3.3(2.3-4.7)$ & $<0.001$ & $18.7(16.8-20.6)$ \\
\hline \multicolumn{5}{|l|}{ Medical } \\
\hline High FIM (>76 points) & 807 & 1.0 & & $11.2(8.1-14.3)$ \\
\hline Middle FIM (60-76 points) & 766 & $1.8(1.3-2.4)$ & $<0.001$ & $17.7(14.5-20.9)$ \\
\hline Low FIM (<60 points) & 562 & $3.2(2.4-4.3)$ & $<0.001$ & $28.7(25.1-32.4)$ \\
\hline \multicolumn{5}{|l|}{ Orthopedic } \\
\hline High FIM (>76 points) & 2,212 & 1.0 & & $6.1(4.7-7.6)$ \\
\hline Middle FIM (60-76 points) & 1,046 & $1.4(1.1-1.9)$ & 0.02 & $8.3(6.4-10.1)$ \\
\hline Low FIM (<60 points) & 306 & $2.2(1.5-3.3)$ & $<0.001$ & $13.5(10.4-16.7)$ \\
\hline
\end{tabular}

NOTE: Abbreviations: APRDRG, all-payer-refined diagnosis-related group; Cl, confidence interval; FIM, Functional Independence Measure; OR, odds ratio; SOI, severity of illness.

${ }^{*}$ Calculated using multivariable logistic regression analysis, adjusting for age, gender, race, APRDRG-SOI expected readmission rate, and marital status as in Table 2 .

${ }^{\dagger}$ Calculated using the least squared means method for the multivariable regression.

failure, may be more likely to result in multiorgan dysfunction that may impair physiological reserve and increase susceptibility to medical complications. ${ }^{28-31}$ In comparison, acute neurologic and orthopedic diagnoses, such as stroke or hip arthroplasty, directly impair gross motor function, ${ }^{32-35}$ with relative sparing of overall physiologic reserve.

The association between low functional status and readmissions is supported by previous studies across multiple hospital settings. ${ }^{4,5,7-9,27,36}$ Despite this finding, routine inpatient medical practice may not fully address functional impairments. For instance, systematic measurement and documentation of functional status on admission and during hospitalization are not routine and may be a barrier to identifying medical patients at high risk for readmission. ${ }^{37-39}$ Moreover, without recognition of functional impairment and its implications, current clinical practice may suboptimally prevent and treat physical impairments during inpatient care. However, such barriers can be surmounted. For example, in the medical intensive care unit setting, there is growing recognition that proactive and aggressive management of hospitalacquired functional impairments through early rehabilitation is safe and feasible, improving patient outcomes while reducing hospital costs and readmissions. ${ }^{3,40-51}$ Moreover, 2 recent meta-analyses have shown that physical therapy hospital-based exercise programs can improve length of stay, overall hospital costs, and rates of discharge to home. ${ }^{52,53}$ Finally, a randomized trial has demonstrated that an individualized exercise regimen started in the acute hospital setting with long-term telephone follow-up can significantly reduce emergency hospital readmissions and improve quality of life in older adults. ${ }^{54}$
Therefore, decreased functional status likely represents a modifiable risk factor for hospital readmission, and further research is necessary to more systematically identify low-functioning patients and implement early mobility and activity programs to reduce hospital-acquired functional impairment. ${ }^{2,49,55}$

Our analysis has potential limitations. First, this was an observational study and we are unable to demonstrate a direct cause-and-effect relationship between functional status and readmission. However, our results are consistent with prior literature in this field. Second, our cohort only included patients who were discharged from an acute hospital to a rehabilitation facility, which may limit its generalizability. However, we included a large patient sample size with a broad range of admission FIM scores, and our findings are consistent with other studies conducted in different clinical settings. Third, although 1 of our goals was to evaluate how readmission rates differed by diagnostic category, it is possible that individual diagnoses within each category may have different risks for readmission, and future larger studies could evaluate more detailed diagnostic grouping approaches. Fourth, we also recognize that although FIM score assessment has been validated, admission assessment occurs over a 72-hour time period, during which patients' function could potentially change a clinically meaningful degree. Fifth, there may be residual confounding because of limitations in available data within our administrative dataset; however, we did account for severity of illness using a standardized measure, and prior research has demonstrated that the relationship between functional status and readmissions may be minimally confounded by demographic and clinical variables. ${ }^{8,16,27,56}$ Finally, we lacked readmission data following discharge from rehabilitation; it is possible that the association between FIM score at the time of rehabilitation initiation may have had limited predictive value among patients who successfully completed rehabilitation and were sent home.

\section{CONCLUSION}

In conclusion, in this study of patients admitted from acute care hospitals to a single inpatient rehabilitation facility, we observed a strong association between decreased functional status and increased hospital readmission. In particular, medical patients with lower physical functioning exhibited an especially high rate of readmission. Incorporating functional status assessment into routine medical care may help identify patients at higher risk of readmission. Moreover, preventing and treating impaired functional status during inpatient admission, through early activity and mobility, should be evaluated as a way of improving patient outcomes and reducing hospital readmissions.

Disclosures: Erik Hoyer, MD, is supported by the Rehabilitation Medicine Scientist Training Program (RMSTP; 5K12HD001097). The authors report no conflicts of interest. 


\section{References}

1. Jencks SF, Williams MV, Coleman EA. Rehospitalizations among patients in the Medicare fee-for-service program. N Engl J Med. 2009; 360(14):1418-1428.

2. Krumholz HM. Post-hospital syndrome-an acquired, transient condition of generalized risk. N Engl J Med. 2013;368(2):100-102.

3. Morris PE, Griffin L, Berry M, et al. Receiving early mobility during an intensive care unit admission is a predictor of improved outcomes in acute respiratory failure. Am J Med Sci. 2011;341(5):373-377.

4. Bohannon RW, Lee N. Association of physical functioning with samehospital readmission after stroke. Am J Phys Med Rehabil. 2004; 83(6):434-438.

5. Coleman EA, Min SJ, Chomiak A, Kramer AM. Posthospital care transitions: patterns, complications, and risk identification. Health Serv Res. 2004;39(5):1449-1465.

6. Smith DM, Katz BP, Huster GA, Fitzgerald JF, Martin DK, Freedman JA. Risk factors for nonelective hospital readmissions. J Gen Intern Med. 1996;11(12):762-764.

7. Kansagara D, Englander H, Salanitro A, et al. Risk prediction models for hospital readmission: a systematic review. JAMA. 2011;306(15): 1688-1698.

8. Ottenbacher KJ, Graham JE, Ottenbacher AJ, et al. Hospital readmission in persons with stroke following postacute inpatient rehabilitation. J Gerontol A Biol Sci Med Sci. 2012;67(8):875-881.

9. Ottenbacher KJ, Smith PM, Illig SB, Peek MK, Fiedler RC, Granger CV. Hospital readmission of persons with hip fracture following medical rehabilitation. Arch Gerontol Geriatr. 2003;36(1):15-22.

10. Ottenbacher KJ, Smith PM, Illig SB, Fiedler RC, Gonzales V, Granger CV. Characteristics of persons rehospitalized after stroke rehabilitation. Arch Phys Med Rehabil. 2001;82(10):1367-1374.

11. Carter G, Relles D, Buchanan J, et al. A classification system for inpatient rehabilitation patients: a review and proposed revisions to the functional independence measure-function related groups. PB98105992, September. Washington, DC: US Department of Commerce, National Technical Information Services; 1997.

12. Stineman MG, Escarce JJ, Goin JE, Hamilton BB, Granger CV, Williams SV. A case-mix classification system for medical rehabilitation. Med Care. 1994;32(4):366-379.

13. Ottenbacher KJ, Hsu Y, Granger CV, Fiedler RC. The reliability of the functional independence measure: a quantitative review. Arch Phys Med Rehabil. 1996;77(12):1226-1232.

14. Stineman MG, Hamilton BB, Granger CV, Goin JE, Escarce JJ, Williams SV. Four methods for characterizing disability in the formation of function related groups. Arch Phys Med Rehabil. 1994;75(12): 1277-1283

15. Oduyebo I, Lehmann CU, Pollack CE, et al. Association of selfreported hospital discharge handoffs with 30-day readmissions. JAMA Intern Med. 2013;173(8):624-629.

16. Hoyer EH, Needham DM, Miller J, Deutschendorf A, Friedman M, Brotman DJ. Functional status impairment is associated with unplanned readmissions. Arch Phys Med Rehabil. 2013;94(10):1951-1958.

17. Averill RF, Goldfield N, Steinbeck BA, et al. All patient refined diagnosis related groups (APR-DRGs). Version 15.0. Report No.: 98-054 Rev. 00. Wallingford, CT: 3M Health Information Systems; 1998.

18. The inpatient rehabilitation facility-patient assessment instrument (IRF-PAI) training manual. 2012. http://www.cms.gov/.

19. Heinemann AW, Kirk P, Hastie BA, et al. Relationships between disability measures and nursing effort during medical rehabilitation for patients with traumatic brain and spinal cord injury. Arch Phys Med Rehabil. 1997;78(2):143-149.

20. Hamilton BB, Laughlin JA, Fiedler RC, Granger CV. Interrater reliability of the 7-level functional independence measure (FIM). Scand J Rehabil Med. 1994;26(3):115-119.

21. Ottenbacher KJ, Smith PM, Illig SB, Linn RT, Fiedler RC, Granger $\mathrm{CV}$. Comparison of logistic regression and neural networks to predict rehospitalization in patients with stroke. J Clin Epidemiol. 2001; 54(11):1159-1165.

22. Wallace D, Duncan PW, Lai SM. Comparison of the responsiveness of the Barthel Index and the motor component of the Functional Independence Measure in stroke: the impact of using different methods for measuring responsiveness. J Clin Epidemiol. 2002;55(9):922-928.

23. Philbin EF, DiSalvo TG. Prediction of hospital readmission for heart failure: development of a simple risk score based on administrative data. I Am Coll Cardiol. 1999;33(6):1560-1566.

24. Gorodeski EZ, Starling RC, Blackstone EH. Are all readmissions bad readmissions? N Engl J Med. 2010;363(3):297-298.

25. Axon RN, Williams MV. Hospital readmission as an accountability measure. JAMA. 2011;305(5):504-505.

26. Bion JF. Susceptibility to critical illness: reserve, response and therapy. Intensive Care Med. 2000;26(suppl 1):S57-S63.

27. Chung DM, Niewczyk P, DiVita M, Markello S, Granger C. Predictors of discharge to acute care after inpatient rehabilitation in severely affected stroke patients. Am I Phys Med Rehabil. 2012;91(5):387-392.

28. Sheu CC, Gong MN, Zhai R, et al. Clinical characteristics and outcomes of sepsis-related vs non-sepsis-related ARDS. Chest. 2010; 138(3):559-567.
29. Yende S, Angus DC. Long-term outcomes from sepsis. Curr Infect Dis Rep. 2007;9(5):382-386.

30. Fonarow GC, Peterson ED. Heart failure performance measures and outcomes: real or illusory gains. JAMA. 2009;302(7):792-794.

31. Holland R, Rechel B, Stepien K, Harvey I, Brooksby I. Patients' selfassessed functional status in heart failure by new york heart association class: a prognostic predictor of hospitalizations, quality of life and death. J Card Fail. 2010;16(2):150-156.

32. Dechartres A, Boutron I, Nizard R, et al. Knee arthroplasty: disabilities in comparison to the general population and to hip arthroplasty using a French national longitudinal survey. PLoS One. 2008;3(7):e2561.

33. Patterson KK, Parafianowicz I, Danells CJ, et al. Gait asymmetry in community-ambulating stroke survivors. Arch Phys Med Rehabil. 2008;89(2):304-310.

34. Nakayama H, Jorgensen HS, Raaschou HO, Olsen TS. Recovery of upper extremity function in stroke patients: The Copenhagen Stroke Study. Arch Phys Med Rehabil. 1994;75(4):394-398.

35. Wong AA, Davis JP, Schluter PJ, Henderson RD, O'Sullivan JD, Read SJ. The effect of admission physiological variables on 30 day outcome after stroke. J Clin Neurosci. 2005;12(8):905-910.

36. Gruneir A, Dhalla IA, van Walraven C, et al. Unplanned readmissions after hospital discharge among patients identified as being at high risk for readmission using a validated predictive algorithm. Open Med. 2011;5(2):e104-e111.

37. Ettinger WH. Can hospitalization-associated disability be prevented? JAMA. 2011;306(16):1800-1801.

38. Covinsky KE, Pierluissi E, Johnston CB. Hospitalization-associated disability: "she was probably able to ambulate, but I'm not sure." JAMA. 2011;306(16):1782-1793.

39. Inouye SK, Peduzzi PN, Robison JT, Hughes JS, Horwitz RI, Concato J. Importance of functional measures in predicting mortality among older hospitalized patients. JAMA. 1998;279(15):1187-1193.

40. Needham DM. Mobilizing patients in the intensive care unit: improving neuromuscular weakness and physical function. JAMA. 2008; 300(14):1685-1690.

41. Needham DM, Truong AD, Fan E. Technology to enhance physical rehabilitation of critically ill patients. Crit Care Med. 2009;37(10 suppl):S436-S441.

42. Needham DM, Korupolu R, Zanni JM, et al. Early physical medicine and rehabilitation for patients with acute respiratory failure: a quality improvement project. Arch Phys Med Rehabil. 2010;91(4):536-542.

43. Lord RK, Mayhew CR, Korupolu R, et al. ICU early physical rehabilitation programs: financial modeling of cost savings. Crit Care Med. 2013;41(3):717-724.

44. Schweickert WD, Pohlman MC, Pohlman AS, et al. Early physical and occupational therapy in mechanically ventilated, critically ill patients: a randomised controlled trial. Lancet. 2009;373(9678):1874-1882.

45. Morris PE, Goad A, Thompson C, et al. Early intensive care unit mobility therapy in the treatment of acute respiratory failure. Crit Care Med. 2008;36(8):2238-2243.

46. Bailey P, Thomsen GE, Spuhler VJ, et al. Early activity is feasible and safe in respiratory failure patients. Crit Care Med. 2007;35(1):139-145.

47. Needham DM, Korupolu R. Rehabilitation quality improvement in an intensive care unit setting: implementation of a quality improvement model. Top Stroke Rehabil. 2010;17(4):271-281.

48. Rubin FH, Neal K, Fenlon K, Hassan S, Inouye SK. Sustainability and scalability of the hospital elder life program at a community hospital. J Am Geriatr Soc. 2011;59(2):359-365.

49. Inouye SK, Bogardus ST Jr, Charpentier PA, et al. A multicomponent intervention to prevent delirium in hospitalized older patients. $N$ Engl J Med. 1999;340(9):669-676.

50. Herridge MS, Tansey CM, Matte A, et al. Functional disability 5 years after acute respiratory distress syndrome. N Engl J Med. 2011; 364(14):1293-1304.

51. Zanni JM, Korupolu R, Fan E, et al. Rehabilitation therapy and outcomes in acute respiratory failure: an observational pilot project. J Crit Care. 2010;25(2):254-262.

52. de Morton NA, Keating JL, Jeffs K. Exercise for acutely hospitalised older medical patients. Cochrane Database Syst Rev. 2007;(1): CD005955.

53. Peiris CL, Taylor NF, Shields N. Extra physical therapy reduces patient length of stay and improves functional outcomes and quality of life in people with acute or subacute conditions: a systematic review. Arch Phys Med Rehabil. 2011;92(9):1490-1500.

54. Courtney M, Edwards H, Chang A, Parker A, Finlayson K, Hamilton K. Fewer emergency readmissions and better quality of life for older adults at risk of hospital readmission: a randomized controlled trial to determine the effectiveness of a 24-week exercise and telephone follow-up program. J Am Geriatr Soc. 2009;57(3):395-402.

55. Flood KL, Maclennan PA, McGrew D, Green D, Dodd C, Brown CJ. Effects of an acute care for elders unit on costs and 30-day readmissions. JAMA Intern Med. 2013:1-7.

56. Stineman MG, Ross R, Maislin G, Fiedler RC, Granger CV. Risks of acute hospital transfer and mortality during stroke rehabilitation. Arch Phys Med Rehabil. 2003;84(5):712-718. 